\title{
A New Device for Internal Fixation of Thoracolumbar and Lumbar Spine Fractures: The 'Fixateur Interne'^
}

\author{
W. Dick, M.D., P. Kluger, M.D., F. Magerl, M.D., O. Woersdörfer, M.D. \\ and G. Zäch, M.D. \\ University of Basle, Kinderspital Basle, Switzerland
}

\section{Summary}

A new system of operative fixation of thoracolumbar and lumbar spine fractures is presented: the 'fixateur interne' (F.I.). From a posterior approach long Schanz screws are inserted through the pedicles into the body of the two vertebrae just adjacent to the lesion and connected by the threaded F.I. rods. By tightening the nuts the Schanz screws are fixed in all directions. The advantages of the F.I. system are: excellent reposition by the long lever-arm of the Schanz screws, immobilization of only two segments and therefore good mobility of the residual spine, stability against flexion forces better than is obtained with Harrington distraction rods, additional rotational stability, and fixation in lordosis or kyphosis as is desired.

The F.I. does not act as a four point bending system like all other dorsal spine instrumentation systems, but provides stability in flexion by itself. Therefore it can be used independently of the condition of all ligaments (including the anterior longitudinal ligament) and of the posterior wall of the fractured vertebrae, and there is no need to fix more than the two immediately adjacent vertebrae, thus avoiding the often painful and cumbersome iatrogenic loss of lumbar lordosis and of mobility and permitting early mobilization of the patient. Experience with the first 45 patients is very promising.

Key words: Thoracolumbar and lumbar spine fractures; Operative treatment; Internal fixation; Use of Schanz screws.

\section{Introduction}

The common implants for internal fixation of thoracolumbar and lumbar spine fractures like Harrington rods, Jacobs rods, Luque rods and dorsal plates have several disadvantages. Stability is often not good enough to permit early mobilization of the patient. Slipped hooks, broken rods and loss of correction 
are not uncommon. (Convery et al., 1978; Dickson et al., 1978; Gertzbein et al., 1982; Purcell et al., 1981; Stauffer and Neil, 1975).

Reduction of the bony fragments can only be achieved by indirect means. Direct adjustment of the position of one particular vertebra is not possible.

The most important disadvantage is unavoidable because it is a biomechanical one: all these systems are based on a two-point-fixation on both sides of the fracture (White et al., 1977). They have a mobile link to one vertebra and need a second bony support on the lamina of the next vertebra. This means that at least five vertebrae, two above and two below the fracture, are included in the fixation (Flesh et al., 1977, Osebold et al., 1981). Jacobs recommends even a three above-three below technique for better stability (Jacobs et al., 1983; Jacobs et al., 1982).

Such a long-length of immobilization of healthy joints cannot be the final solution in spinal surgery. Similar techniques on the upper and lower extremities would never be accepted. It is well known that paraplegic patients with a stiff thoracolumbar or lumbar spine and with an iatrogenic loss of lumbar lordosis have rehabilitation problems (Bedbrook, 1979; Hasday et al., 1983). Often, even the later removal of the implant after fracture healing has occurred does not solve the problem (Holm and Nachemson 1982), because the mobility of the temporarily instrumented part of the spine is not restored regardless if long fusion or short fusion was intended. To overcome these disadvantages the senior authors (W.D. and F.M.) have developed a spinal fixation device which is based on a different mechanical principle. We call it 'Fixateur interne' or F.I.instrumentation (Dick, 1984).

\section{The implant}

Using the usual dorsal approach, long Schanz screws are driven through the pedicles into the vertebral bodies until their tip lies close to the anterior aspect of the vertebral bodies. With some experience the correct points of entry dorsally can be easily found. The Schanz screws are inserted parallel to the end plate and convergent 10 to 15 degrees towards the middle. They are selftapping. The screws are lying within the closed cortical bone of the pedicles and do no harm to the neural structures. They obtain a very firm hold in the bone.

The Schanz screws are connected together with threaded rods. The connective chuks and jaws are at first able to move in any direction. They permit kyphosis, lordosis, distraction, compression, or rotation, and can be finally fixed by nuts in any desired position. Thus the Schanz screws are held in a stable angle towards each other. As long as the hinges remain secure, no redislocation will occur.

\section{Advantages}

This means that the Fixateur interne is stable by itself. No second point of bony support is required. The instrumentation can be restricted to the immediately adjacent vertebra above and below the fracture, and it does not matter if the posterior elements are fractured, or the ligaments are torn: never are more than three vertebrae immobilized (Fig. 1).

We have tested the stability of the instrumentation on a universal testing 


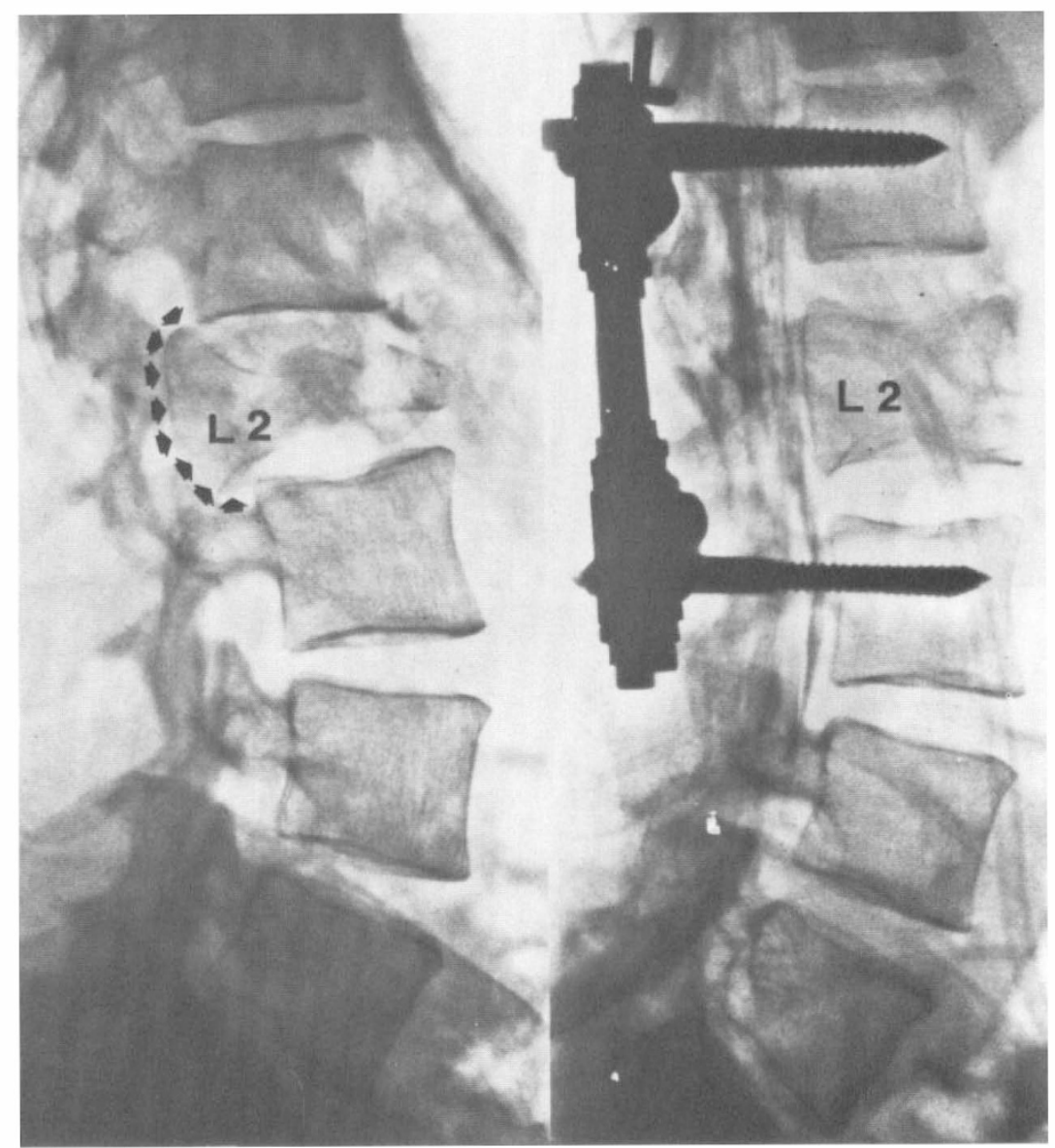

Figure 1. Burst fracture of the second lumbar vertebra with incomplete paraplegia. Reduction and fixation by F.I.-instrumentation without laminectomy. Post-operative myelogram demonstrates the anatomical reduction of the posterior wall of the spinal canal.

machine: the range of elasticity of the device itself reaches $40 \mathrm{Nm}$ anterior bending moment. From 40 to $70 \mathrm{Nm}$ a slight permanent deformation occurs without loosening of the hinges.

Loading human cadaver spines with an experimental combined anterior and posterior lesion by a pure anterior bending moment showed that with the F.I. better stability was achieved than with Harrington distraction rods. With excessive loading, the F.I. did not disengage in the way that Harrington hooks may do, nor did the hinges loosen. The limiting factor was a slow dissolution of the spongy bone around the Schanz screws with a non-physiological load (Dick, 1984).

To date, the experimental results are confirmed by the clinical experience with 45 patients: Figure 2 (A, B and C) shows a highly unstable and dislocated lumbar spine fracture. Using reduction and stabilization by the F.I., the patient was out of bed 3 weeks after the accident. Healing was normal. There was no secondary kyphosis after routine removal of metal 10 months later. 

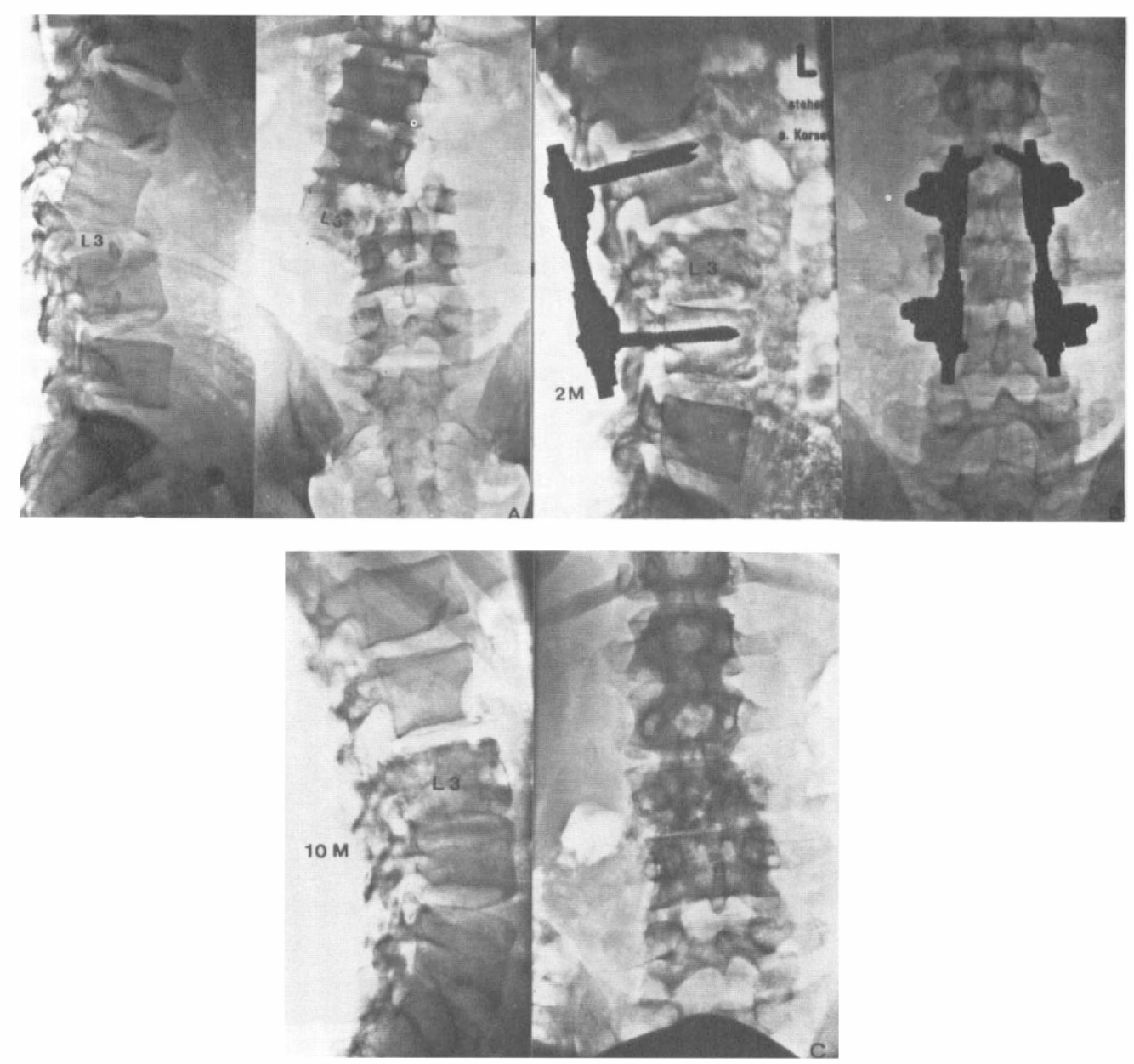

Figure 2. (A) Highly unstable juxation-fraction of third lumbar vertebra. (B) Open reduction by the lever-arms of transpedicular Schanz screws; stabilization of L2-4 with F.I.-

instrumentation. Bedrest for only 3 weeks. (C) The result after removal of the implant after 10 months: physiological lumbar lordosis, fusion of only L3-4.

The second advantage of the F.I. besides it's shortness, are the long lever-arms of the Schanz screws. These handles permit a direct and forceful adjustment of a single vertebra in any desired direction. If present, gross luxations of vertebrae are reduced first by hand with the help of the Schanz screws, then the connecting rods are applied. Next, the vertebral body is spread up anteriorly by posteriorly compressing together the ends of the lever-arms. With this manoeuver the kyphotic deformity is reduced, then the hinges are locked. In the third stage of the technique, the original height of the fractured vertebra can be restored by longitudinal distraction on the threaded rod. With this manoeuver fragments of the posterior wall are reduced if the posterior longitudinal ligament is intact. An example is given in Figure 3 (A, B and C). At the end of the procedure, when the instrumentation has been completed and the nuts are secured, the protruding 


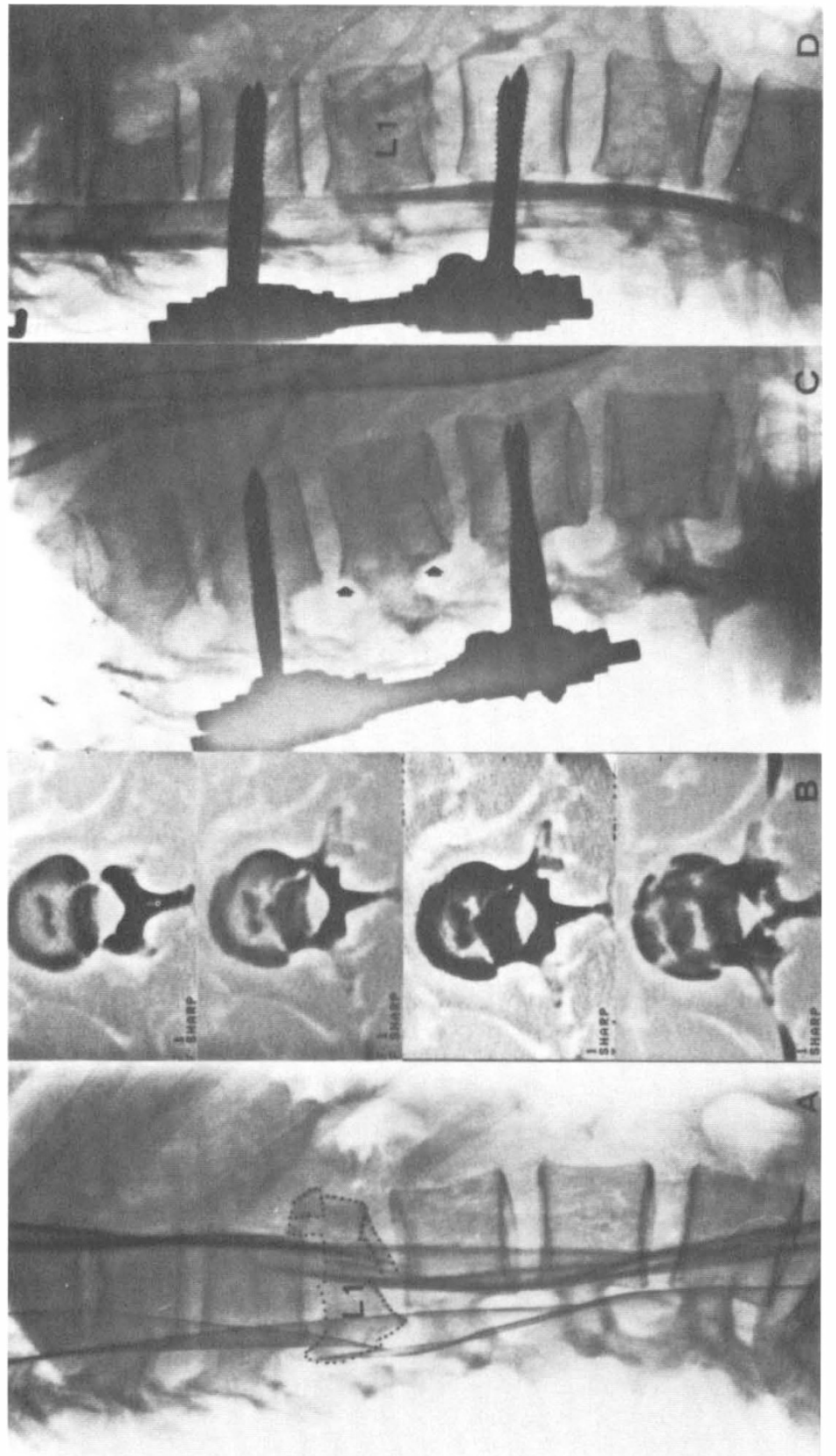

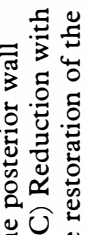
Ư

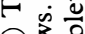

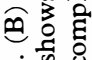
过 เํㄹ 졔 3 过 $>5$ 若证 ह 票家 药 स्ञ 论 4 要 苞苔总. 要浔 语

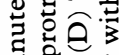
药主 룽.

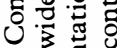
¿蓆 政 m 동 证究出 
parts of the Schanz screws are cut with a Harrington cutter. Wound closure poses no problem.

The third advantage of the F.I. is that it can also be used in the same way after laminectomy or if there is traumatic destruction of all the posterior elements. The position of the Schanz screws in such patients is even easier because the remnants of the pedicles adjacent to the dura can be seen directly.

\section{Bone grafting}

An important problem is the loss of bone anteriorly in compressive spinal fractures after reduction. Instead of a posterior bony fusion we prefer direct grafting along with the F.I.-instrumentation, from the same posterior approach. One or both of the pedicles of the fractured vertebra are opened with a $5 \mathrm{~mm}$ drill bit as proposed by Daniaux (1982). Through this canal the defect in the vertebral body can be filled with small pieces of autologous cancellous bone, using a slightly curved impactor. Surprisingly, a large amount of bone is necessary. A posterior fusion is not then necessary because of the solid anterior healing, as we have seen in our patients.
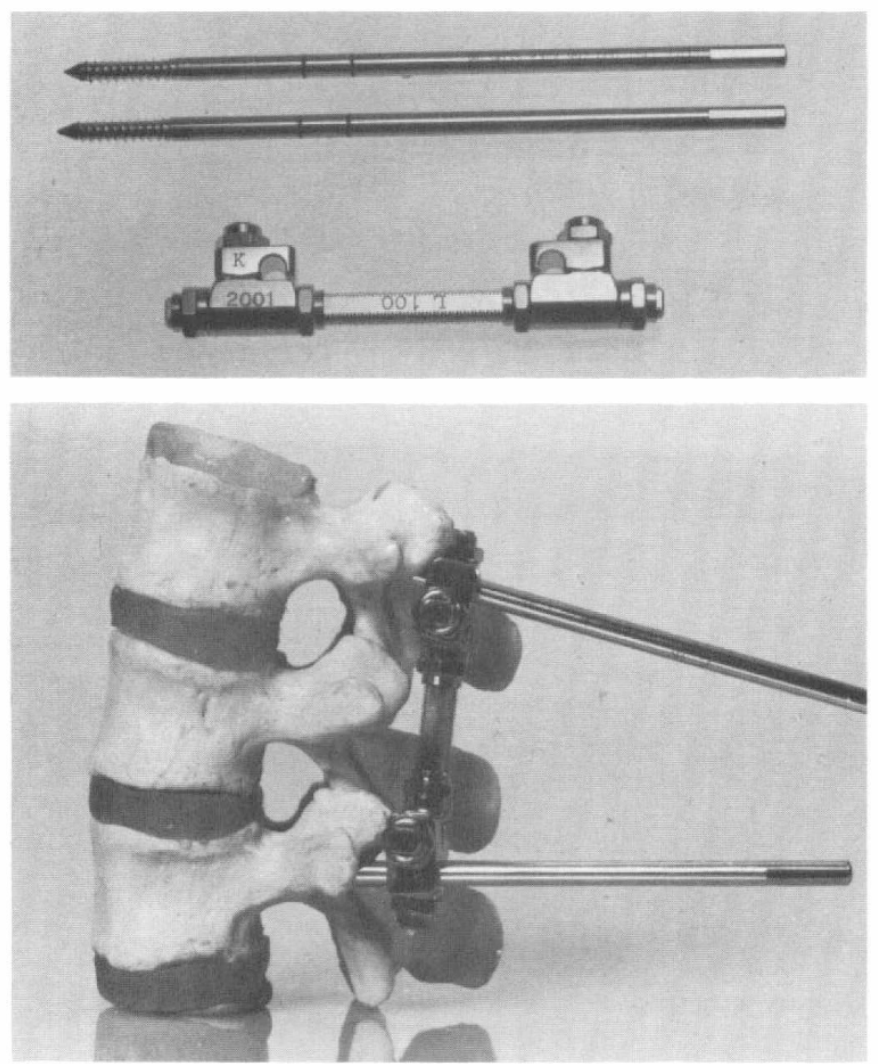

Figure 4. Illustration of the 'Fixateur interne'. The long lever-arms of the Schanz screws, which permit direct and forceful reduction of the fragments, are cut near the threaded rods and the wound can be closed easily. 


\section{Conclusion}

It is not intended to discuss neurological recovery in the F.I. cases here. We feel that there is agreement that neurological recovery depends on the primary lesion itself, on the quality and time of reduction which also means decompression by reduction, and on the absence of secondary neural involvement, and on further re-dislocation. But it does not depend on conservative or operative treatment, nor is it influenced by the kind of implant. We agree with the work published by Frankel et al. (1969).

By this preliminary presentation we want to show:

(1) That the F.I. with the long lever-arms of the Schanz screws is very helpful for the reduction of severely dislocated spines.

(2) That very impressive functional gain was seen in three patients when we replaced failed long rod instrumentations by the short F.I. system.

(3) That a solid two-segmental stabilization of spinal fractures from D8 to the sacrum is possible regardless of the type of fracture, without important iatrogenic loss of mobility and of lumbar lordosis.

(4) That in our 45 patients there was no neurological deterioration or root problem. One patient with severe polytrauma and hepatitis died from pulmonary -mbolism after 3 weeks. His spine was studied and there was excellent stability

$J$ to an anterior bending moment of $47 \mathrm{Nm}$. After removal of the rods there ras complete disrupture of the broken spine with $9 \mathrm{Nm}$. In one patient a secondary kyphosis of 10 degrees developed because of lateral malposition of one Schanz screw. One patient had a wound infection (Staphylococcus aureus) from the 6th to the 16th week, which responded to treatment with antibiotics. There was uneventful bony healing. Removal of the implant after 7 months did not give rise to a secondary kyphosis.

(5) That no full plaster or plastic jacket was applied. Patients were mobilised after 2 to 4 weeks and wore a light prefabricated three-point-support for 8 weeks.

Our experience with the short F.I.-instrumentation in 45 patients leads us to abandon Harrington, Jacobs, or Luque-rods for the treatment of fractures of the lower thoracic and the lumbar spine. The device for internal fixation was changed, but not the indications for operative treatment.

\section{Résumé}

Un nouveau système pour le traitement des fractures dorsolombaires et lombaires est présenté: le 'fixateur interne'. Par voie postérieure, de longues vis de Schanz sont introduites à travers l'intérieur des pédicles dans les corps vertébraux et connectées par les tiges du F.I. d'une manière stable. Les avantages sont: reposition excellente à l'aide du longue bras de levier des vis de Schanz, immobilisation seulement de deux segments, stabilité contre les forces de flexion supérieure à l'instrumentation de distraction de Harrington, stabilité rotatrice supplémentaire, fixation en lordose ou cyphose anatomique, l'usage indépendent de l'état du mur postérieur des corps vertébraux, ou des ligaments ou des éléments posterieurs. L'expérience très favorable avec 45 cas a montré que la perte iatrogène de lordose et de mobilité lombaire peut être évitée.

\section{Zusammenfassung}

Mit dem 'Fixateur interne' wird ein neues Implantat zur Reposition und Stabilisation von Frakturen der Brust- und Lendenwirbelsäule vorgestellt, das nicht wie die gebräuchlichen Systeme biomechanisch auf der vierpunktbiegung beruht, sondern in sich selbst winkel- und rotationsstabil ist. 
Dadurch brauchen in die Fixation lediglich die beiden unmittelbaren Nachbarwirbel der Fraktur einbezogen zu werden, sodass nur zwei Bewegungssegmente versteift werden. Vom dorsalen Zugang aus werden lange Schanzschrauben durch die Pedikel in die Wirbelkörper eingedreht und mit den Fixateurstäben miteinander verbunden. Die Vorteile neben der kurzen Versteifungsstrecke sind: Erleichterung der Reposition durch die langen Hebelarme der Schanzschrauben, Fixation in jeder gewünschten Lordose oder Kyphose möglich, Anwendbarkeit unabhängig vom Zerstörungsgrad der Wirbelhinterwand, der Ligamentketten und der dorsalen Pfeiler, Eigenstabilität ausreichend zur Frühmobilisation der Patienten mit leichtem Dreipunktmieder ohne Schalenkorsett. Die Erfahrung erstreckt sich auf 45 Fälle.

\section{References}

BEDBROOK GM 1979 Spinal injuries with tetraplegia and paraplegia. Journal of Bone and Joint Surgery 61B:267-284

Convery FR, Minteer MA, SMith RW, Emerson SM 1978 Fracture-dislocation of the dorsolumbar spine. Acute operative stabilization by Harrington instrumentation. Spine 3:160-166

Daniaux H 1982 Technik und erste Ergebnisse der transpedikulären Spongiosaplastik bei Kompressionsbrüchen im Lendenwirbelsäulenbereich. Acta Chirurgica Austriaca, Supplement 43:79

DICK W 1984 Innere Fixation von Brust- und Lendenwirbelbrüchen. Bern-Stuttgart-Wien: Hans Huber

Dickson JH, Harrington PR, ERwin WD 1978 Results of reduction and stabilization of the severely fractured thoracic and lumbar spine. Journal of Bone and Joint Surgery 60A:799-805

Flesh JR, Leider LL, ERICKSON DL, Chou SN, Bradford DS 1977 Harrington instrumentation and spine fusion for unstable fractures and fracture-dislocations of the thoracic and lumbar spine. Journal of Bone and Joint Surgery 59A:143-153

Frankel HL, Hancock DO, Hyslop G, Melzak J, Michaelis LS, Ungar GH, Vernon JDS, WALSH JJ 1969 The value of postural reduction in the initial management of closed injuries of the spine with paraplegia and tetraplegia. Paraplegia 7:179-192

GertZBein SD, MaCmichael D, Tile M. 1982 Harrington instrumentation as a method of fixation in fractures of the spine. A critical analysis of deficiencies. Journal of Bone and Joint Surgery 64B:526-529

Hasday CA, PASSOFF TL, PeRry J 1983 Gate abnormalities arising from iatrogenic loss of lumbar lordosis secondary to Harrington instrumentation in lumbar fractures. Spine 8:501-511

Holm St, Nachemson A 1982 Nutritional changes in the canine intervertebral disc after spinal fusion. Clinical Orthopaedics 169:243-258

Jacobs RR, Dahners LE, Gertzbein S, Nordwall A, Mathys R 1983 A locking hook-spinal rod: current status of development. Paraplegia 21:197-207

Jacobs RR, NoRDWALl A, NACHEMSON AL 1982 Reduction, stability, and strength provided by internal fixation systems for thoracolumbar spinal injuries. Clinical Orthopaedics 171:300-308

OSEBOLD WR, WEINSTEIN SL, SPRAGUE BL 1981 Thoracolumbar spine fractures: results of treatment. Spine 6: 13-34

Purcell GA, Markolf KL, Dawson EG 1981 Twelfth thoracic-first lumbar vertebral mechanical stability of fractures after Harrington rod instrumentation. Journal of Bone and Joint Surgery 63A:71-78

STAUFFER ES, NeIL JL 1975 Biomechanical analysis of structural stability of internal fixation in fractures of the thoracolumbar spine. Clinical Orthopaedics 112:159-164

White AA, PANJabi MM, Thomas CL 1977 The clinical biomechanics of kyphotic deformities. Clinical Orthopaedics 128:8-17 